\title{
Variation in the mitochondrial control region sequence between the two maternal lines of the Sorraia horse breed
}

\author{
Cristina Luís ${ }^{1}$, Cristiane Bastos-Silveira ${ }^{1,2}$, E.Gus Cothran ${ }^{3}$ and M. Mar Oom ${ }^{1}$ \\ ${ }^{1}$ Centro de Biologia Ambiental / DZA, Faculdade de Ciências, Universidade de Lisboa, \\ Lisboa, Portugal. \\ ${ }^{2}$ Department Biology, University College of London, Gower Street, London, UK. \\ ${ }^{3}$ Department of Veterinary Science, University of Kentucky, Lexington, USA.
}

\begin{abstract}
The mitochondrial control region sequence was compared between the two surviving matrilineal lineages of the Sorraia horse. Two haplotypes were found, showing three differences between them. The reduced number of surviving maternal lineages emphasizes the importance of establishing a conservation plan for this endangered breed.
\end{abstract}

Key words: Sorraia horse, mitochondrial DNA, maternal lineages, control region.

Received: July 8, 2002; accepted: July 31, 2002.

\section{Introduction}

Understanding the evolution and genetic diversity of equids and classifying their populations by their evolutionary significance is essential for an appropriate conservation plan to be developed and carried out for both wild and captive populations (Oakenfull et al., 2000). Mitochondrial DNA analysis has been widely used to study wild and domestic equids, mainly due to the evolutionary information that can be drawn from sequence data (Bowling et al., 2000; Kavar et al., 1999; Kim et al., 1999; Oakenfull and Ryder, 1998; Oakenfull et al., 2000; Vilà et al., 2001).

Sorraia, one of the three Portuguese native horse breeds, was recovered by Dr. Ruy d'Andrade in 1937, from 12 founders: 5 males and 7 females. It is considered a primitive horse and is believed to be the ancestor of the southern Iberian saddle horse breeds and possibly one of the ancestors of the entire world's light saddle horses (Andrade, 1926, 1937, 1945; Bouman, 1989; Oom, 1992; Oom and Cothran,1994). Therefore, the phylogenetic relationships among Sorraia and other horse breeds is of interest for conservation measures that may be implemented for this rare (Galal and Hammond, 1996) and very endangered breed. Moreover, such studies can help to reach a better understanding of the history of some horse breeds, especially those of the New World, where the Iberian influence is very important.

Send correspondence to Maria do Mar Oom. Centro de Biologia Ambiental/DZA, Faculdade de Ciências,Universidade de Lisboa, Campo Grande, C2-3ํㅗ Piso, 1749-016 Lisboa, Portugal. E-mail: moom@fc.ul.pt.
With less than 160 living animals, the Sorraia breed consists presently of two major subpopulations: the founding one in Portugal, and another one in Germany, established in 1976 from six animals imported from Portugal, with no further immigration (Oom and Luís, 2001).

According to pedigree data, seven of the 12 founders were females, but only two maternal lineages (Azambuja and Cigana) have survived along 64 breeding years (Figure 1). Therefore, no more than two different mitochondrial lineages would be expected to exist in the living animals of the breed. As all female founders of the German population share tail-female lineage drawn back to founder Cigana, only one maternal line is expected to exist in the descendants of that population. In this study we present sequence results of $360 \mathrm{bp}$ of the hypervariable control region zone between $\mathrm{TRNA}^{\mathrm{Thr}}$ and the large conserved block.

\section{Material and Methods}

Three and four representatives, respectively, of each of Sorraia's two surviving maternal lineages were selected by pedigree, to test haplotype uniformity within pedigree female founder lines. The individuals chosen, as identified by their Studbook identification number (NSNC), were the following: 50162, 52191 and 66139 descending from mare Azambuja; 52159, 52206, 94099 and 94112 descending from mare Cigana.

DNA was extracted from fresh whole blood samples following a high salt extraction procedure (Montgomery and Sise, 1990), and from whole blood samples, stored 

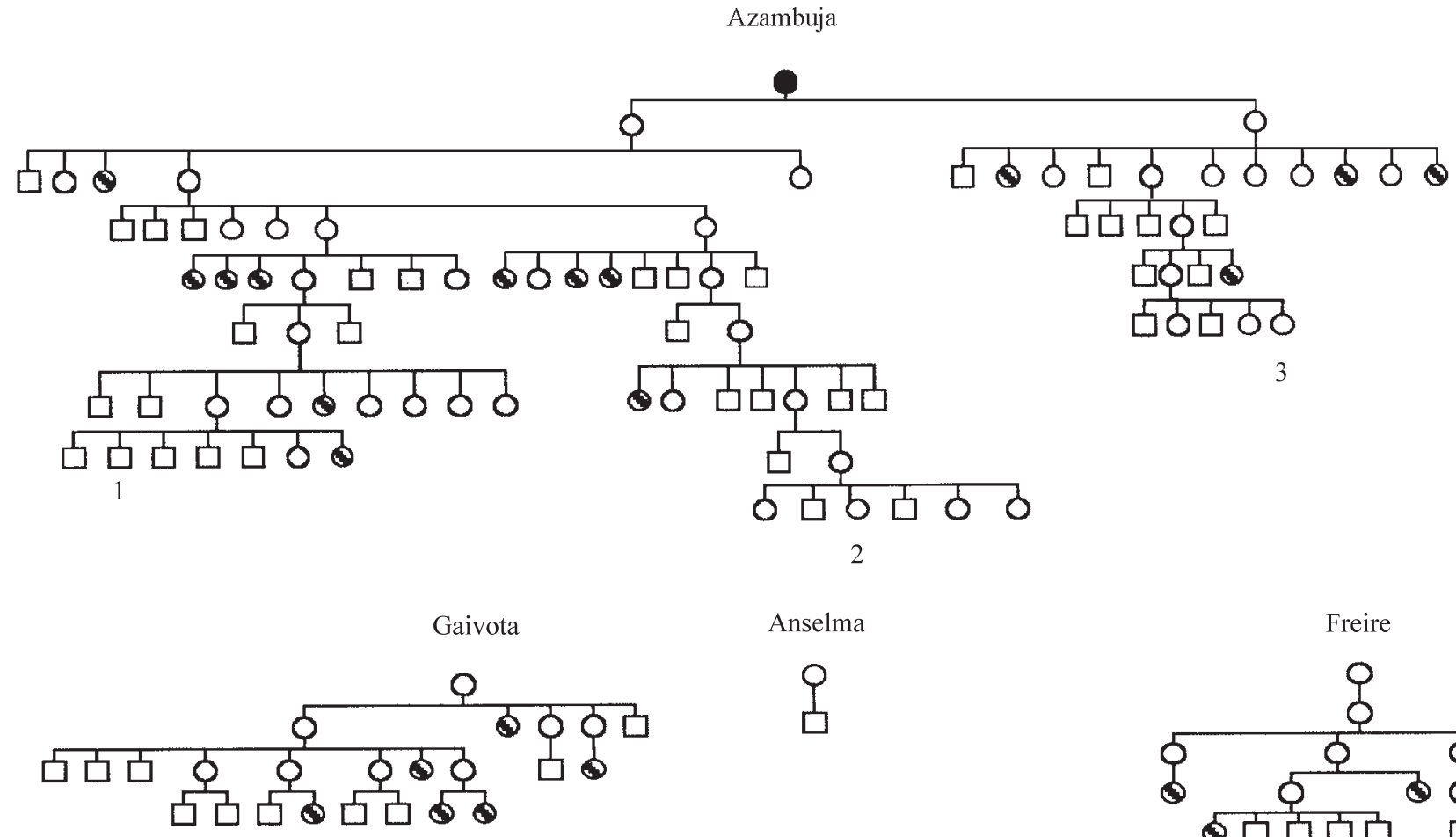

Anselma
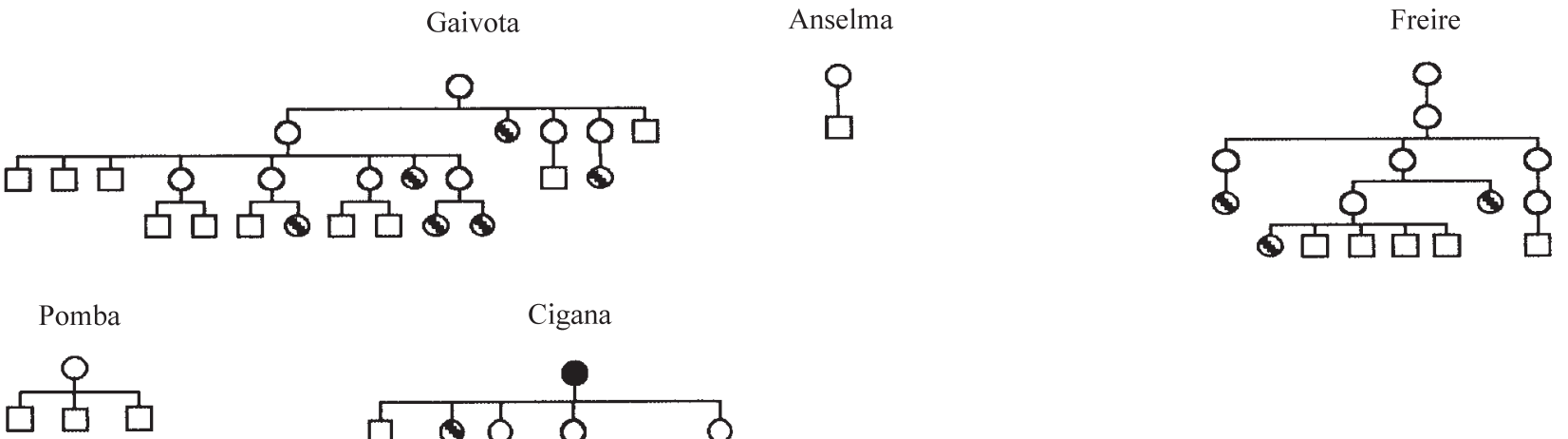

Cigana

Garrana

9

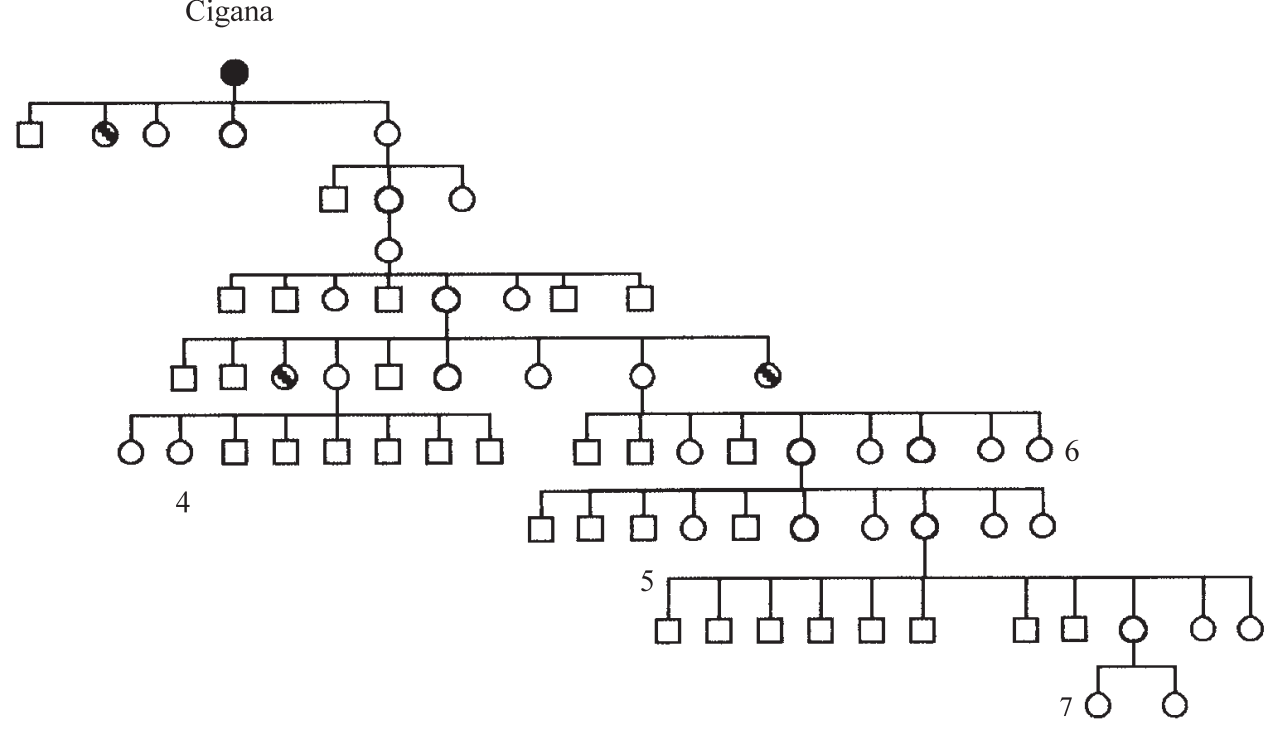

Figure 1 - Pedigrees of maternal lines of the Sorraia breed. Open square - male; open circle - female with progeny; filled circle - female founder with a surviving maternal line; slashed circle - female without progeny. Numbers indicate the analyzed samples: 1 - 66139; 2 - 50162;3 - 52191; 4 - 52206; 5 94099; 6 - 52159; 7 - 94112 .

since 1988 at $-20{ }^{\circ} \mathrm{C}$, by using the QIAmp Mini Blood Kit (Quiagen).

Universal primers L15926 and H16498, designed by Kocher et al. (1989), were used to amplify a 360 bp fragment between sites 15411 and 15770 (control region) of the horse mitochondrial genome (Xu and Árnason, 1994). The amplification conditions were: 2 min denaturation at $95^{\circ} \mathrm{C}$, 25 cycles, each consisting of $40 \mathrm{~s}$ denaturation at $95^{\circ} \mathrm{C}, 30 \mathrm{~s}$ annealing at $55^{\circ} \mathrm{C}$ and $30 \mathrm{~s}$ extension at $70^{\circ} \mathrm{C}$, final extension at $72^{\circ} \mathrm{C}$ for $8 \mathrm{~min}$. Sequencing was performed on both strands, twice for each sample, using the CycleReader ${ }^{\mathrm{TM}}$ Auto DNA Sequencing Kit (MBI Fermentas), with IRD 800- labeled PCR primers used as sequencing primers. Sequences were determined with a Li-Cor 4200S Sequencer and analyzed with Li-Cor Image Analysis software. 
Table I - Sorraia horse haplotype sequences and nucleotide substitutions among the control region sequences, as compared to the reference sequence GenBank X79547. The dots indicate concordance with GenBank X79547. Azambuja and Cigana are the two maternal lines analyzed.

\begin{tabular}{|c|c|c|c|c|c|c|c|c|c|c|c|}
\hline & \multirow[b]{2}{*}{ Haplotype } & \multicolumn{10}{|c|}{ Position of nucleotide substitutions relative to GenBank X79547 (15411-15770) } \\
\hline & & $\begin{array}{l}\stackrel{a}{+} \\
\stackrel{1}{2}\end{array}$ & 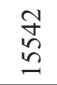 & $\begin{array}{l}n \\
\infty \\
n \\
n\end{array}$ & $\begin{array}{l}\hat{2} \\
\hat{n}\end{array}$ & $\begin{array}{l}\text { ¿̊ } \\
\text { D } \\
n\end{array}$ & $\begin{array}{l}n \\
\hat{0} \\
\curvearrowleft\end{array}$ & $\begin{array}{l}0 \\
0 \\
n \\
n\end{array}$ & $\begin{array}{l}\circ \\
: \\
:\end{array}$ & 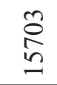 & $\begin{array}{l}\text { N } \\
\text { in }\end{array}$ \\
\hline Individuals & X79547 & $\mathbf{T}$ & $\mathbf{C}$ & G & $\mathbf{A}$ & $\mathbf{C}$ & $\mathbf{C}$ & $\mathbf{A}$ & G & $\mathbf{T}$ & G \\
\hline $\begin{array}{l}52191,50162, \\
66139\end{array}$ & $\begin{array}{l}\text { Azambuja } \\
\text { AF447764 }\end{array}$ & $\mathrm{C}$ & $\mathrm{T}$ & . & G & $\mathrm{T}$ & $\mathrm{T}$ & G & A & $\mathrm{C}$ & A \\
\hline $\begin{array}{l}52159,52206 \\
94112,94099\end{array}$ & $\begin{array}{l}\text { Cigana } \\
\text { AF447765 }\end{array}$ & $\mathrm{C}$ & $\mathrm{T}$ & A & G & $\mathrm{T}$ & & $\mathrm{G}$ & A & . & A \\
\hline
\end{tabular}

\section{Results and Discussion}

The samples analyzed provided evidence for 2 haplotypes of the control region in the Sorraia horse. Individuals belonging to the same maternal line, either Azambuja or Cigana, presented the same mitochondrial haplotype, corroborating pedigree data. In addition, both samples from the German population (52159 and 94099) had the same haplotype (Cigana). Table I shows the differences in the control region between the two maternal lineages and the reference sample (Swedish horse - GenBank X79547).

The two Sorraia haplotypes found for the Azambuja and Cigana lineages (nucleotide sequences deposited in GenBank with accession numbers AF447764 and AF447765, respectively) differ from the reference sample by eight to nine nucleotide substitutions, and from each other by three sites. These samples showed a total of ten base substitution sites (all transitions), no insertions or deletions having been observed.

The analysis of mitochondrial DNA of the Sorraia horse enhances the importance of establishing an effective management and conservation plan for this endangered breed, in order to prevent the two remaining matrilineal lineages from being lost in the near future. It may also be a valid test for the integrity of the German Sorraia population, as only one matrilineal line is present there. These results also provide important material for an ongoing study about the evolution and origins of this breed and its relations to other equine breeds, in order to preserve its evolutionary potential.

\section{Acknowledgments}

C. Luís and C. Bastos-Silveira were supported by $\mathrm{PhD}$ grants from the Portuguese Foundation for Science and Technology (SFRH/BD3318/2000 and PRAXIS $\mathrm{XXI} / \mathrm{BD} / 13421 / 97$, respectively).

\section{References}

Andrade R, d' (1926) Apontamentos para um estudo sobre a origem e domesticação do cavalo na Península Ibérica. Aproximações. Centro Tipográfico Colonial, Lisboa, 30 pp.
Andrade R, d' (1937) Les chevaux du Sorraia. Comptes Rendues: 2368-2370. XII Congrès International de Zoologie, Lisboa, Portugal.

Andrade R, d' (1945) O Cavalo do Sorraia. Boletim Pecuário XIII:1-13.

Bouman I (1989) Origins of the domestic horse. Przewalski Horse 23:32-43.

Bowling AT, Del Valle A and Bowling M (2000) A pedigreebased study of mitochondrial D-loop DNA sequence variation among Arabian horses. Anim Genet 31:1-7.

Galal S and Hammond K (1996) The global program for the management of farm animal genetic resources. III Iberoamerican Congress on native and Creole Breeds, 25-30 November, Santa Fe de Bogota D.C., Colombia.

Kocher TD, Thomas WK, Meyer A, Edwards SV, Pääbo S, Villablanca FX and Wilson AC (1989) Dynamics of mitochondrial DNA evolution in animals: amplification and sequencing with conserved primers. Proc Natl Acad Sci USA 86:6196-6200.

Kavar T, Habe F, Brem G and Dove P (1999) Mitochondrial D-loop sequence variation among the 16 maternal lines of the Lipizzan horse breed. Anim Genet 30:423-430.

Kim K-I, Yang Y-H, Lee S-S, Park C, Ma R, Bouzat JL and Lewin HA (1999) Phylogenetic relationships of Cheju horses to other horse breeds as determined by mtDNA D-loop sequence polymorphism. Anim Genet 30:102-108.

Montgomery GW and Sise JA (1990) Extraction of DNA from sheep white blood cells. N. Z. J Agric Res 33:437-441.

Oakenfull EA and Ryder AO (1998) Mitochondrial control region and 12S rRNA variation in Przewalski's horse (Equus przewalskii). Anim Genet 29:456-459.

Oakenfull EA, Lim HN and Ryder AO (2000) A survey of equid mitochondrial DNA: Implications for the evolution, genetic diversity and conservation of Equus. Cons Genet 1:341-355.

Oom MM (1992) O cavalo Lusitano. Uma raça em recuperação. PhD Thesis, University of Lisbon, Lisbon, Portugal.

Oom MM and Cothran EG (1994) The genetic variation of an endangered breed: the Sorraia horse. Anim Genet 27:35.

Oom MM and Luís C (2001) The Sorraia horse (Portugal): genetic variation and genetic management of an endangered breed. Conservation Genetics Meeting, 12-14 September, Lausanne, Switzerland.

Vilà C, Leonard JA, Götherström A, Marklund S, Sandberg K, Lidén K, Wayne RK and Ellegren H (2001) Widspread origins of domestic horse lineages. Science 291:474-477.

Xu X and Árnason Ú (1994) The complete mitochondrial DNA sequence of the horse, Equus caballus: extensive heteroplasmy of the control region. Gene 148:657-662. 